\title{
INFLUENCES ON MENARCHEAL AGE IN GIRLS IN A WELSH COLLEGE
}

\author{
BY \\ D. F. ROBERTS AND T. C. DANN \\ From the Laboratory of Human Genetics, University of Newcastle upon Tyne, and University College, Swansea
}

Of the methods used to obtain estimates of the mean and dispersion of age at menarche in a population, the potential accuracy of two are generally agreed: the prospective method, in which individuals are followed in longitudinal studies throughout the pubertal period, and the status quo method, in which probits or logits are fitted to data from Yes/No questions to girls of known age in the range 9 to 17 years. These two procedures avoid many of the errors and biases that may arise from cross-sectional retrospective studies in which girls are asked to recollect their age when they first started to menstruate. Such errors may arise from the difficulty of exact recollection; this is particularly so in the case of older women but may also occur at younger ages, for De Wijn (1966) showed that the percentage of teenage girls unable to recollect the exact month increases with the age at which they are asked; but errors of recollection do not always occur, as was shown by Livson and McNeill (1962), who compared recorded age with that remembered 17 years later and found close individual and very close mean concordance. Much depends on the intelligence of the girl and on the clarity of definition of the event. There may be bias if there are any girls in the sample who have not yet menstruated or who give deliberately false answers to emulate their friends; for example, Kark (1943) showed that girls of 18 to 20 gave an average age remembered as 15 to 16 years, whereas those of 15 to 17 gave an average age of 13 to 14 years; Wilson and Sutherland (1949), comparing two groups of children in Oxford and in Oxfordshire, showed that the difference in their respective remembered ages (13.4 and 13.09 years respectively), was entirely due to the inclusion of more pre-pubertal girls in the latter sample, for probit analysis showed an identical mean age $(13 \cdot 6)$ for both groups. This is not to say, however, that all cross-sectional surveys are of little value, and indeed many such studies have provided useful information. If one can rely on the intelligence of the girl questioned, if her memory can be trusted in respect of what is an important phenomenon in her life, if that phenomenon has not occured in the too remote past, and if the total sample questioned is of such an age that there is no individual within it who has not yet attained menarche, then reliable information can be forthcoming and proper estimates of menarcheal age in the sample obtained. Indeed an efficient crosse sectional survey of modest size can provide a great deal more information on the effects of a number of simultaneously-acting variables than would be forthcoming only from a much larger survey analysed by the probit method, and at much less expense than would be incurred in a longitudinal survey.

The present study relates to such a cross-sectional investigation. In the medical examination of all girls admitted to the University College of Swansea at the time of their admission, during the period 1959 to 1965 , the question was asked as to the age at menarche; this was recorded as the age at birthday preceding menarche. Any girl about whose answer there was any doubt was excluded from the analysis. The sample can be regarded as relating to girls of adequate intelligence and reliable memory, all questioned between the ages of 18 and 21 (there were a few considerably older women in the intake but these have been excluded from the analysis). They were thus all born in a period of considerable economic stringency and nutritional uniformity. The data seemed worth putting on record for their intrinsic interest in the light of the much discussed secular trend to earlier menarcheal age. Moreover their relative homogeneity, it was thought, might allow some assessment of the relative importance of the secular component of variation in relation to the total variability that other factors affecting development produce. 


\section{RESULTS}

The total sample consisted of 931 girls born in 1939 and later, who were admitted as students to the college in the years 1959-62, 1964, and 1965. About half the girls (477) were born in Wales (most of these (288) in Glamorgan) and the remainder in England; any born elsewhere were excluded from the study. As a preliminary, the mean menarcheal age for each year's intake was calculated as set out in col. 7 of Table I.

From this preliminary tabulation there appeared to be a trend over the period to progressive diminution in mean menarcheal age which, on examination by simple linear regression of menarcheal age on year of intake for all girls, proved to be highly significant $(\mathrm{F}=7.01 ; \mathrm{P}<\cdot 01 ; y=15.6445-.0486 x$, where $y$ equals menarcheal age in years and $x$ equals year of intake less 1900). Further examination seemed to be called for.

\section{Five-Variable ANALysis}

The following variables were considered for each girl:

$(Y)$ menarcheal age in years, recorded as age at birthday preceding;

$\left(X_{1}\right)$ year of birth, less 1900 ;

$\left(X_{2}\right)$ the number of siblings she has;

$\left(X_{8}\right)$ the numerical position of the girl in the family;
$\left(X_{4}\right)$ the father's occupation described numerically as in the Registrar General's classification. The weakness of the last figure as a numerical estimator is freely admitted, but it was considered worth retaining in the analysis to give some indication of the order of socio-economic status, which the alternative, analysis within classes, would not give. Special care was taken to ascertain accurately the type of work performed.

The means for each year's intake are set out in Table I. There seems to have been a tendency for girls of the earliest two intakes to have come from slightly larger families, but this is not significant. There is also apparently a trend over the years for an increase, which is highly significant, in the occupational status of the father, since the lower the number assigned the higher the social category: whether this implies that later intakes are more preponderantly from better socio-economic classes, or whether it means that more fathers now describe their occupations in a form which places them in a better category, is not clear, but the former seems more likely from subjective impressions.

The year of intake was considered of little relevance to the following analysis and was excluded. A multiple regression analysis was performed to examine the association of menarcheal age with the other four variables. The zero order correlation coefficients are as set out in Table II.

TABLE I

VARIATES BY YEAR OF INTAKE

\begin{tabular}{|c|c|c|c|c|c|c|c|c|c|c|c|}
\hline \multirow{2}{*}{$\begin{array}{l}\text { Year of } \\
\text { Intake }\end{array}$} & \multirow{2}{*}{$\begin{array}{l}\text { No. in } \\
\text { Sample }\end{array}$} & \multicolumn{2}{|c|}{ Year of Birth } & \multicolumn{2}{|c|}{ No. of Siblings } & \multicolumn{2}{|c|}{ Position in Family } & \multicolumn{2}{|c|}{ Father's Occupation } & \multicolumn{2}{|c|}{ Menarcheal Age (yrs) } \\
\hline & & mean & s.d. & mean & s.d. & mean & s.d. & mean & s.d. & mean* & s.d. \\
\hline $\begin{array}{l}1959 \\
1960 \\
1961 \\
1962 \\
1964 \\
1965\end{array}$ & $\begin{array}{r}71 \\
77 \\
139 \\
161 \\
207 \\
276\end{array}$ & $\begin{array}{l}40 \cdot 51 \\
41 \cdot 25 \\
42 \cdot 28 \\
43 \cdot 43 \\
45 \cdot 45 \\
46 \cdot 44\end{array}$ & $\begin{array}{r}.75 \\
.88 \\
.85 \\
.69 \\
.79 \\
1.04\end{array}$ & $\begin{array}{l}1 \cdot 55 \\
1.95 \\
1.24 \\
1.08 \\
1 \cdot 21 \\
1.38\end{array}$ & $\begin{array}{l}1.58 \\
1.11 \\
1.24 \\
.97 \\
1.17 \\
1.43\end{array}$ & $\begin{array}{l}1 \cdot 62 \\
1.60 \\
1.52 \\
1.50 \\
1.58 \\
1.59\end{array}$ & $\begin{array}{r}1.11 \\
.85 \\
.84 \\
.73 \\
1.04 \\
.97\end{array}$ & $\begin{array}{l}2 \cdot 77 \\
2 \cdot 65 \\
2 \cdot 60 \\
2 \cdot 57 \\
2 \cdot 28 \\
2 \cdot 49\end{array}$ & $\begin{array}{l}1 \cdot 12 \\
1 \cdot 10 \\
1.15 \\
1.03 \\
1.09 \\
1.13\end{array}$ & $\begin{array}{l}12.94 \\
12.69 \\
12.60 \\
12.61 \\
12 \cdot 46 \\
12.54\end{array}$ & $\begin{array}{l}1 \cdot 22 \\
1.07 \\
1.05 \\
1.20 \\
1 \cdot 14 \\
1 \cdot 13\end{array}$ \\
\hline
\end{tabular}

To make these figures (which relate to age at birthday preceding menarche) comparable with estimates from the probit method, 0.5 should be added.

TABLE II

ZERO ORDER CORRELATION COEFFICIENTS: 5-VARIABLE ANALYSIS

\begin{tabular}{|c|c|c|c|c|c|c|c|c|}
\hline & & & & $x_{1}$ & $X_{2}$ & $x_{8}$ & $x_{6}$ & $\boldsymbol{Y}$ \\
\hline$X_{1}$ Year of birth &.. & .. & .. & - & -.0134 & -.0208 & $-\cdot 1054 t$ & $-\cdot 1061 t$ \\
\hline$X_{\mathbf{2}}$ No. of siblings & .. & .. & .. & & - & $+.6350 t$ & +.0350 & $+.0712^{*}$ \\
\hline$X_{\mathbf{Z}}$ Position in sibship .. & .. & .. & .. & & & - & $+\cdot 0428$ & -.0481 \\
\hline$X_{\triangleleft}$ Father's occupation & .. & .. & .. & & & & - & -.0477 \\
\hline
\end{tabular}


With the exception of the obvious correlation between position in family and size of family, all correlation coefficients are low. However, there is a slight positive significant correlation of menarcheal age with family size, and a highly significant negative correlation of menarcheal age with year of birth. There is also a highly significant negative correlation between year of birth and father's occupation. The associations of menarcheal age with year of birth and family size are presumably biological in origin, indicating that there is a trend to a steadily lower age at menarche, and that in larger families menarche tends to be slightly delayed.

The other significant correlation between father's socio-economic group and year of birth represents the tendency, shown by the table of means for each year's intake, to improved occupational status of the fathers of girls admitted to college in successive intakes.

However, the interpretation of such significant but low zero order associations is open to error if there is inter-correlation, as in this case, between the variables. Partial regressions were therefore calculated, the coefficients (in standard and actual measure) being shown in Table III.

From these values the regression was calculated as $Y=15 \cdot 3146-.05769 X_{1}+\cdot 15414 \quad X_{2}-\cdot 19128$ $X_{3}-.06044 X_{4}$. Of the four regression coefficients, the first three (with year of birth, number of siblings, and position in family) were highly significant at $\cdot 001$, and the fourth (with father's occupation) was not quite significant at $\cdot 05$; the $t$ values are shown in the Table. These implement the interpretations of the zero order associations. It appears that menarcheal age is steadily becoming earlier in this sample at a rate that is detectable even in the few years the sample spans; that it tends to be delayed in girls of larger families; but that girls born later in a family of a given size have earlier menarches, a tendency which is independent of the secular trend. However, despite the high level of significance of these regression coefficients considered singly, and of the total regression for which the multiple correlation coefficient $R=\cdot 1859$, it is remarkable how little of the total variation in menarcheal age these four independent variates account for-over 96 per cent. of the total variation remains to be explained.

\section{Six-VARIABle AnAlysis}

Information is available on one other variable of possible relevance, the body build of the individual. This was measured as $\frac{\text { Stature }}{\sqrt[3]{\text { Weight }}}$ and ranged from 10.68 for the plumpest to 14.30 for the most slender. Unfortunately this information is not available for the total sample as it was not measured on the 1965 intake and so the statistical parameters that follow are not directly comparable with those in the preceding discussion. Preliminary analysis of variance showed significant differences in physique between intakes, the means for which are set out in Table IV. The same multiple regression procedure was followed for the 655 individuals on whom information was available.

\begin{tabular}{c|c|c|c}
\multicolumn{5}{c}{ TABLE IV } \\
PONDERAL INDEX $\frac{\text { STATURE }}{3 \sqrt{\text { WEIGHT }}}$ BY YEAR OF INTAKE \\
\hline Year of Intake & No. in Sample & Mean & S.D. \\
\hline 1959 & 71 & $12 \cdot 72$ & .39 \\
1960 & 77 & $12 \cdot 60$ & .51 \\
1961 & 139 & $12 \cdot 70$ & .48 \\
1962 & 161 & $12 \cdot 79$ & .57 \\
1964 & 207 & $12 \cdot 77$ & .52 \\
\hline
\end{tabular}

Of the zero order correlation coefficients set out in Table V (opposite) only two are highly significant, that between $X_{2}$ and $X_{3}$ as expected (between the number of siblings and the numerical position of the girl in the family), the other between physique and menarcheal age, the latter being the largest of all the

TABLE III

PARTIAL REGRESSION COEFFICIENTS OF MENARCHEAL AGE ON EACH INDEPENDENT VARIATE

Zero order correlation of $Y$ with $X$

Standard regression coefficients of $Y$ on $X$

Regression coefficients of $Y$ on $X$..

Values of $t$

\begin{tabular}{|c|c|c|c|}
\hline$X_{1}$ & $X_{2}$ & $X_{3}$ & $X_{4}$ \\
\hline$-\cdot 10613$ & +.07121 & -.04808 & -.04765 \\
\hline$-\cdot 11331$ & $+\cdot 17124$ & $-\cdot 15666$ & -.05889 \\
\hline-.05769 & $+\cdot 15414$ & $-\cdot 19128$ & -.06044 \\
\hline $3 \cdot 49^{*}$ & $4 \cdot 10^{*}$ & $3 \cdot 73^{*}$ & $1 \cdot 81$ \\
\hline
\end{tabular}

* Significant at $\cdot 01$. 
TABLE V

ZERO ORDER CORRELATION COEFFICIENTS: 6-VARIABLE ANALYSIS

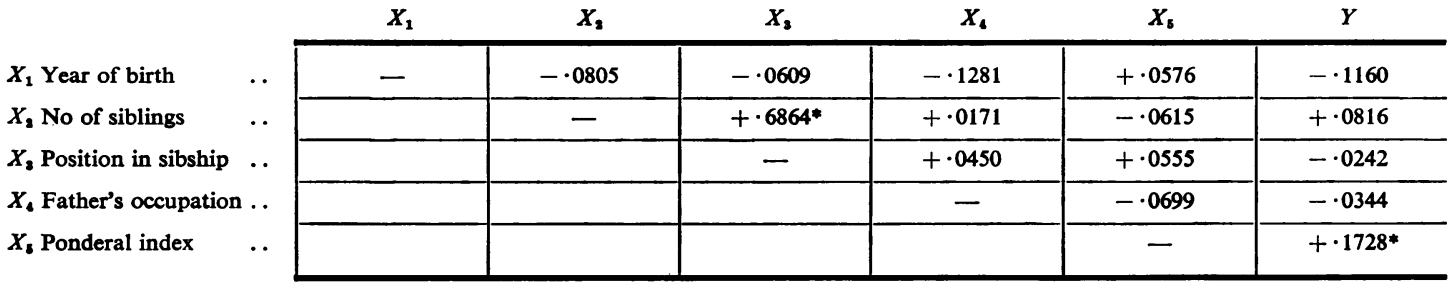

* Significant at $\cdot 01$.

remaining correlation coefficients. Two others approach significance, that between year of birth and father's occupation, and that between menarcheal age and year of birth. None of the remainder approaches significance, the difference in significance from those set out in Table II indicating the loss of nearly a third of the degrees of freedom as a result of the lower sample size. The partial regression coefficients are shown in Table VI. These are very similar to those obtained when only five variables were considered, high significance levels being attained by the regression coefficients of menarcheal age on year of birth, number of siblings, and position in family. The regression on father's occupation is far from significant and it seems that this variable is of no importance to the daughter's menarcheal age. The most striking effect, however, is produced by the additional variable, physique. Its effects are quite independent of the associations with year of birth and family size and position in family, as is shown by the fact that the regression coefficients are almost unchanged from the previous analysis. The inclusion of physique in the analysis produces a considerable augmentation of the multiple correlation coefficient $R=\cdot 2525$. Again, however, even with the inclusion of this further variable, the major part of the total variation in menarcheal age remains unexplained, over 93 per cent.

One further source of possible variation was examined. The girls born in Wales were divided according to county of birth (Table VII), since ABO blood groups and other characters show that there is some genetic heterogeneity between counties. The number of girls in any one English county in any year were too few for a similar analysis. While there is a suspicion that lower mean menarcheal age tends to be characteristic in those counties that are most urbanized, analysis of variance showed no significant differences between counties. However, the counties were very unevenly represented in the sample, there being a marked lack of individuals from central Wales and few from the north; the

TABLE VII

MENARCHEAL AGE IN GIRLS BORN IN WALES, BY COUNTY

\begin{tabular}{|c|c|c|c|}
\hline \multirow{2}{*}{ County of Birth } & \multirow{2}{*}{ No. in Sample } & \multicolumn{2}{|c|}{ Menarcheal Age (yrs) } \\
\hline & & Mean* & S.D. \\
\hline $\begin{array}{l}\text { Glamorgan } \\
\text { Monmouth } \\
\text { Carmarthen } \\
\text { Cardigan } \\
\text { Merioneth } \\
\text { Caernarvon } \\
\text { Pembroke } \\
\text { Flint } \\
\text { Denbigh } \\
\text { Anglesey } \\
\text { Brecon } \\
\text { Montgomery } \\
\text { Radnor }\end{array}$ & $\begin{array}{r}288 \\
75 \\
47 \\
11 \\
4 \\
10 \\
10 \\
4 \\
15 \\
4 \\
6 \\
2 \\
1\end{array}$ & $\begin{array}{l}12 \cdot 58 \\
12 \cdot 47 \\
12 \cdot 68 \\
12 \cdot 91 \\
13 \cdot 00 \\
12 \cdot 70 \\
12 \cdot 60 \\
11 \cdot 50 \\
12 \cdot 80 \\
13 \cdot 25 \\
13 \cdot 33 \\
12 \cdot 50 \\
13 \cdot 00\end{array}$ & $\begin{array}{r}1 \cdot 16 \\
1 \cdot 35 \\
1 \cdot 11 \\
1 \cdot 04 \\
\cdot 82 \\
\cdot 83 \\
1 \cdot 17 \\
1 \cdot 29 \\
1 \cdot 08 \\
1 \cdot 26 \\
\cdot 52 \\
\cdot 71 \\
0\end{array}$ \\
\hline
\end{tabular}

* To make these figures (which relate to age at birthday preceding menarche) comparable with estimates from the probit method, 0.5 should be added.

TABLE VI

PARTIAL REGRESSION COEFFICIENTS OF MENARCHEAL AGE ON EACH INDEPENDENT VARIATE

\begin{tabular}{|c|c|c|c|c|c|c|}
\hline & & $x_{1}$ & $X_{2}$ & $X_{3}$ & $X_{4}$ & $X_{5}$ \\
\hline Zero order correlation of $Y$ with $X$ & . & $-\cdot 11602$ & .08164 & -.02422 & $-\cdot 03443$ & $\cdot 17282$ \\
\hline Standard regression coefficient of $Y$ on $X$ & .. & $-\cdot 12649$ & $\cdot 16789$ & $-\cdot 15540$ & -.03422 & $\cdot 17603$ \\
\hline Regression coefficient of $Y$ on $X$.. & .. & -.07583 & $\cdot 16147$ & $-\cdot 19401$ & $-\cdot 03545$ & $\cdot 39208$ \\
\hline Values of $t \ldots$ & .. & $3 \cdot 29 *$ & $3 \cdot 21^{*}$ & $3 \cdot 50^{*}$ & $0 \cdot 89$ & $4 \cdot 59 *$ \\
\hline
\end{tabular}

- Significant at $\cdot 01$. 
present results cannot therefore be taken as indicating that no geographical effect exists, but only that the present data are inadequate to demonstrate it.

\section{Discussion}

While it is not possible to ensure the accuracy of any cross-sectional retrospective investigation, as has been pointed out by many, the nature of the present sample and the care taken in screening the data, it is hoped, have rendered the present investigation as free from bias and error as any such study can be. No girl had not attained menarche at the time of examination.

The estimates of mean menarcheal age are concordant with other recent figures from Britain, all obtained from probit analysis. In adolescent girls examined in London in 1959 the mean was 13.1 (Tanner's 1962 recalculation of the data of Scott, 1961); in Bristol in 1956 it was 13.2 (Wofinden and Smallwood, 1958); in Edinburgh in 1952-3 it was 13.4 (Provis and Ellis, 1955); in Dorset and Essex in 1949 it was 13.5 (Wilson and Sutherland, 1950); in Oxford in 1948 it was 13.6 (Wilson and Sutherland, 1949). These figures relate to mean menarcheal age at the time of investigation; it is not possible to relate them to year of birth, so their comparison with our present data is general rather than exact. Our 1959 intake, born predominantly in 1940, give a mean, adjusted for the different method of collection, of $13 \cdot 4$, very similar to the Edinburgh figure relating to girls born on average the year previously. Our 1962 intake with a mean birth year comparable with the Bristol sample gives an adjusted mean of $13 \cdot 1$, again very similar.

Tanner $(1962,1965)$ drew together data from European and American sources, and showed that the trend to earlier menarche was generally similar in all series, amounting to about 4 months per decade over the period 1830 to 1960 . By comparison with this overall regression of approximately .033 years per year, our zero order regression coefficients on year of birth of -.070 (in the more restricted sample), and -.054 (in the full sample), and the corresponding partial coefficients of -.076 and $-\cdot 058$, seem to be somewhat high; the possibility cannot be ignored that there was some acceleration of the trend in girls born during and just after the war years. However, since the standard errors of our partial coefficients are respectively .023 and -017, the difference of our estimates from Tanner's overall figure is less than $\mathbf{2}$ standard errors and so is not significant. It seems that the secular trend here shown is compatible in rate with other esti- mates. But there is a slight suspicion, though again not significant, from comparison of the regression coefficients excluding the 1965 intake $(\cdot 070)$ and including the 1965 intake $(\cdot 054)$, that the trend may be decelerating, and further data are clearly required to follow this. A discussion of changes in menarcheal age led Brown (1966) to conclude that two processes were at work in the 19th and 20th centuries; one of these he suggests affected only part of the population and was associated with the elimination of delaying factors such as chronic infections and nutritional deficiencies. Such a process is unlikely to have been operating to any appreciable extent during the period of development of our present sample. The rate of secular change that occurs in it by comparison with that operating throughout the last century, suggests that this process was not of appreciable importance over the whole period.

Some of the earliest writings on the subject from Guarinonius (1610) and Buffon (1798) record that earlier menarche occurs in girls from well-to-do families, and an effect of socio-economic status is shown by the consensus of studies in other countries. For example, De Wijn (1966) in the west Netherlands found a mean menarcheal age of 13.8 in girls whose fathers were predominantly in the lower and middle social classes, and of 13.5 in those from Social Classes 1 and 2. In Copenhagen (Bojlen; Rasch, and Weis-Bentzon, 1954), there was a similar but smaller difference of 2 months between the means in daughters of professional men and of unskilled workmen. More pronounced differences were found in samples in north-east Slovenia (Kralj-Cerček, 1956), where for girls of good, medium, and poor social origins the mean menarcheal ages were $13 \cdot 3,13 \cdot 7$, and $14 \cdot 2$ years. In Hong Kong (Lee, Chang, and Chen, 1963), Chinese girls from rich, average, and poor families showed means of $12 \cdot 5,12 \cdot 8$, and $13 \cdot 3$ years. In American Negroes comfortably situated in New York (Michelson, 1944), there was an 8 months difference from their poorer compatriots in the southern U.S.A. In Indians in Durban (Kark, 1956), the mean menarche was 6 months earlier in the rich than in the poor. By contrast, the present analysis shows no detectable effect of socio-economic status. That this is not due to the present treatment of social class as a numerical variable was shown by analyses of variance and covariance within and between classes; class differences were far from significant. The results are thus compatible with other recent English (Douglas, 1964) and Scottish (Nisbet and Illsley, 1963) studies which, using classifications respectively dissimilar and similar to ours, have shown no 
significant differences in menarcheal age between girls whose fathers were in different socio-economic groups. One explanation is that the environmental and particularly nutritional differences that separate the socio-economic groups overseas are much more pronounced than they now are in Great Britain; certainly during the years of birth and early development of the girls studied here they were virtually eliminated. Alternatively, it may mean that the categories by which socio-economic classes are distinguished in Britain are no longer meaningful in terms of housing standards, expenditure on food, etc.

Our demonstration of an effect of family size, later menarche being associated with the greater number of siblings, is not surprising. Valšík, Štukovský, and Bernátová (1963) showed that, by comparison with the mean age when there are two children in a family, the average menarcheal age rises by more than 5 weeks with every further pair of children. The same trend occurred in the data obtained by Soenderop, Winter, and Neelsen (1961), and in Great Britain by Douglas (1964) and Scott (1961). The magnitude of Valsík's effect (approximately -05 years per sib), however, is comparable with our zero order regression coefficient $(\cdot 071)$. That the full effect of sib number in his study was masked by other influences is suggested by our partial regression analysis, which shows a rate some three times as high $(\cdot 154$ years per sib, with a standard error of $\cdot 038$ ), and so suggests that sib number is an appreciably more important influence on menarcheal age. This effect parallels what is observed in physical growth where the number of children in the family affects the children's rate of growth, particularly in poorer families (Tanner, 1962) and a simple environmental explanation has been proposed; the more mouths to feed and children to care for, the lower the standards of feeding and general care attained, and thus family size merely extends the general socio-economic effect on growth. The parallel is not exact, of course, for physical growth still shows a socio-economic effect in Great Britain in most recent studies whereas menarcheal age does not, but if this explanation is accepted it implies that family size is a more accurate indicator of nutritional hardship in Great Britain than the Registrar General's categories generally used-a chastening reflection on the welfare state.

The finding of an effect of position in family is curious in its direction and magnitude. A girl born sixth in a large sibship can be expected to attain menarche a year earlier than a girl born first in a sibship of comparable size, and this effect is independent of the secular trend. If the size of family exerts its influence through economic factors, one might have expected that those born later in large sibships, and so exposed for all their life to more rigorous conditions, would have been more severely affected than those born earlier, but for this the position effect is in the wrong direction; perhaps therefore it is the younger sibs who are favoured at the expense of the older. A possible explanation is that later sibs tend to develop more rapidly than earlier ones in such ways as skill in eating, use of the body, development of conversation; Brown (1966) has argued the possibility of change in psycho-sexual environment as a factor in the secular trend to earlier menarche, and it is possible that such a factor may enter into the birth rank effect. Of relevance here is a curious finding from a cross-cultural study by Whiting (1965) that early menarche is usual in those societies where there is a high score measuring separation of infant from the mother. If a supplementary explanation of the family-size effect is that children with more sibs get more diseases to slow down their general development, although the evidence for permanent retardation of maturation by disease is scanty, then perhaps children born later in large sibships contract more diseases earlier in life and so have a longer period to make good any retarding effects they may produce. Another possibility is that the position effect is related to the increased maternal age at birth of later children. These are pure speculations, and only stress the need for further investigation of development by birth order in larger families.

The relationship of menarcheal age to physique is well established. Before the beginning of the 20th century it was known that girls who were tall before puberty began adolescence earlier than those who were short; ante-pubertal physique effects have been confirmed by numerous studies down to the details of subcutaneous fat thickness (Garn and Haskell, 1960). Moreover, menarcheal age is also correlated with post-pubertal physique, differences in childhood persisting into adulthood (Shuttleworth, 1939). Our findings of the importance of the menarcheal correlation of ponderal index, with girls of more linear physique experiencing later menarche, are in agreement with the consensus of such studies, showing once again that the physique effect remains into early adulthood at least.

But perhaps the most interesting finding that emerges from this analysis is not so much the occurrence, direction, and magnitude of the effects of all these variables, nor of their independence of each other, but rather how little of the total variation in menarcheal age they account for when taken singly or in combination. This analysis 
considers as independent variates nearly all environmental factors currently held to influence menarcheal age, except direct measurement of nutrient intake. It is likely that other environmental variables would be similarly small or even smaller in size of effect. The problem therefore remains of explaining the ample variability that is left. Of other possible factors the most important are genetic. The limited data that exist on this topic indicate fairly high correlations of menarcheal age between mothers and daughters and between sisters, and a considerably higher correlation between identical twins; while the mean difference in menarcheal age between identical twins is much less than the differences between non-identical twins and between pairs of singleton sisters, which are in turn less than between pairs of unrelated women (Popenoe, 1928; Gould and Gould, 1932; Reymert and Jost, 1947; Petri, 1934; TisserandPerrier, 1953). The sibling correlations remain high when account is taken of communality of fatness and the interaction of fatness and maturation (Garn and Rohmann, 1966). These correlations suggest that menarcheal age is very largely under hereditary control, which is multifactorial in nature like that governing many other developmental features. Thoma (1960) indeed estimated the heritability as between $72 \cdot 2$ and $97 \cdot 7$ per cent. It is on establishing the genetic basis of menarcheal age, and the proportion of the total variability for which heredity alone is responsible, that future investigations of menarche could with profit concentrate.

\section{Summary AND CoNClusions}

A multiple regression analysis was undertaken of menarcheal age in girls admitted to the University College of Swansea between 1959 and 1965. The estimates of mean menarcheal age are concordant with data from other parts of Britain for girls of corresponding birth years. A significant secular trend to diminishing menarcheal age is shown, at a rate that is concordant with, or possibly slightly higher than, the rate over the last century. Family size influences menarcheal age more markedly than was formerly thought, later menarche occurring in girls with greater numbers of siblings. There is also a significant effect of position in family, girls born later in sibships tending to mature earlier. The wellestablished association of menarcheal age with physique, girls of more linear physique experiencing later menarche, is again observed. The effects of all these variates are independent of each other. No association was found with socio-economic status, as assessed by the Registrar General's classification of the father's occupation. These findings and their implications are discussed.
Acknowledgement is gratefully made to Mrs Marjorie Smith for her very considerable computational help.

\section{REFERENCES}

Backman, G. (1948). Acta anat., 4, 421.

Brown, P. E. (1966). Brit. J. prev. soc. Med., $20,9$.

Bojlen, K. W., Rasch, G., and Weis-Bentzon, M. (1954). Acta obstet. gynaec. scand., 33, 405.

Buffon, G. de (1798).. "Histoire naturelle", ed. Saugrain, L'an VII, vol. 20, p. 90 . Paris (Cited by Backman, 1948).

De Wijn, J. F. (1966). In "Somatic Growth of the Child", ed. J. Ten Bosch and A. Haak, pp. 16-24. Stenfert Kroese, Leyden.

Douglas, J. W. B. (1964). "The Home and the School". MacGibbon and Kee, London.

Garn, S. M., and Haskell, J. A. (1960). Amer. J. Dis. Child., 99, 746.

and Rohmann, C. G. (1966). Pediat. Clin. N. Amer., $13,353$.

Gould, H. N., and Gould, M. R. (1932). J. Amer. med. Ass., 98, 1349.

Guarinonius, H. (1610). "Die Grewel der Verwüstung menschlichen Geschlechts". Ingolstadt (Cited by Backman, 1948).

Kark, E. (1943). Sth Afr. J. med. Sci., 8, 35.

-(1956). Sth Afr. J. Lab. clin. Med., $2,84$.

Kralj-Cercek, L. (1956). Hum. Biol., 28, 393.

Lee, M. M. C., Chang, K. S. F., and Chan, M. M. C. ̊ (1963). Pediatrics, 32, 389.

Livson, N., and McNeill, D. (1962). Hum. Biol., 34, 218

Michelson, N. (1944). Amer. J. phys. Anthrop., N.S.2, 151 .

Nisbet, J. D., and Illsley, R. (1963). Brit. J. educ. Psychol.," 33, 169.

Petri, E. (1934). Z. Morph. Anthrop., 33, 43.

Popenoe, P. (1928). Eugen. News, 13, 101.

Provis, H. S., and Ellis, R. W. B. (1955). Arch. Dis. Childh., 30, 328.

Reymert, M. L., and Jost, H. (1947). Child. Develop., 18, 169.

Scott, J. A. (1961). "Report on the Heights and Weights (and Other Measurements) of School Pupils in the County of London in 1959". London County Council.

Soenderop, E., Winter, K., and Neelsen, U. (1961). Dtsch. Gesundh.-wes., 16, 1485.

Shuttleworth, F. Kay (1939). Monographs Soc. Res. Child. Dev., 4 , No. 3.

Tanner, J. M. (1962). "Growth at Adolescence", 2nd ed.

Blackwell, Oxford. Maturation", in "Biological Aspects of Social Problems" ed. J. E. Meade and A. S. Parkes, pp. 40-65. (Eugenics Society Symposia, vol. 1). Oliver and Boyd, Edinburgh.

Thoma, A. (1960). Acta biol. Acad. Sci. hung., 11, 241.

Tisserand-Perrier, M. (1953). J. Genet. hum., 2, 87.

Valšik, J. A., Stukovský, R., and Bernátová, L. (1963). Biotypologie, 24, 109.

Wilson, D. C., and Sutherland, I. (1949). Brit. med. J., 2,130 .

W (1950). Ibid., 2, 862.

Wofinden, R. C., and Smallwood, A. L. (1958). Annual Report of the Principal School Medical Officer to City and County of Bristol Education Committee.

Whiting, J. W. M. (1965). In "Sex and Behavior", ed. F. A. Beach, p. 221. Wiley, INew;York. 